\title{
Modeling and Analysis of Ticketing Channel Choice for Intercity Bus Passengers: A Case Study in Beijing, China
}

\author{
Jun Li $\mathbb{D}$, ${ }^{1,2}$ Shunping Jia $\mathbb{D}^{1},{ }^{1}$ Sijia Zhang $\mathbb{D}^{1},{ }^{1}$ and Yuqiong Wang ${ }^{1}$ \\ ${ }^{1}$ School of Traffic and Transportation, Beijing Jiaotong University, Beijing 100044, China \\ ${ }^{2}$ China Transport Telecommunications \& Information Center, Beijing 100011, China \\ Correspondence should be addressed to Jun Li; 14114227@bjtu.edu.cn
}

Received 3 January 2019; Revised 16 May 2019; Accepted 15 July 2019; Published 8 August 2019

Academic Editor: Shamsunnahar Yasmin

Copyright (c) 2019 Jun $\mathrm{Li}$ et al. This is an open access article distributed under the Creative Commons Attribution License, which permits unrestricted use, distribution, and reproduction in any medium, provided the original work is properly cited.

\begin{abstract}
Buses represent the main mode for intercity passenger transportation in China. In recent years, a multichannel ticketing strategy has been widely employed in the bus passenger transportation industry. However, the mechanisms and key drivers of the channels through which bus passengers purchase tickets are underexplored. Thus, the aim of this study is to empirically apply an integrated choice and latent variable (ICLV) approach to analyze ticketing channel choice behavior and the heterogeneous preferences of bus passengers. The variables incorporated in the model include the socioeconomic characteristics of passengers, trip attributes, and latent attitudes with 12 ordinal indicators. Based on the data of 1800 participants collected from the city of Beijing, China, this study develops a ticketing channel choice ICLV model merging a discrete choice model with a structural equation model. The key factors that affect the channel preference are further discussed through a comparison with a conventional multinomial logit (MNL) model. The results reveal that the three attitudinal variables have a significant influence on ticketing channel choice. Furthermore, this study indicates that perceptual differences exist due to various socioeconomic and trip characteristics. Personal privacy is a major obstacle that prevents passengers from choosing online channels, especially for older passengers and those with lower education.
\end{abstract}

\section{Introduction}

Over the last decade, the multichannel strategy has become widely employed in various fields. It has also been targeted from the perspective of the transportation industry in recent years. Passenger transportation operation organizations are selling their tickets or services via multiple channels to reduce distribution costs and provide passengers with convenient service. Taking the example of bus passenger transportation in China, there was only a single channel (counter service at the station) from which passengers purchased tickets for a long period of time. In order to overcome the disadvantages resulting from the limitation of utilizing only a single ticketing channel, together with the integration of modern information technology, bus passenger transportation agencies have developed multiple distribution channels to reserve tickets, such as service counters and ticket vending machines (tvms) at stations, ticketing agencies, websites, mobile apps, etc. The use of multiple channels may result in tremendous savings in monetary and non-monetary costs from a passenger's perspective. Consequently, the ticketing behavior of bus passengers has gradually changed and it is expected to be reconstructed, especially during the holidays. During 40 days of the Spring Festival in 2018, a total of 2.97 billion passengers were reported to have traveled, of which 2.48 billion traveled by bus transportation. A survey from a third party suggested that $63 \%$ of the bus passengers used online channels to purchase tickets. A multichannel strategy for ticketing services makes travelers feel better and more satisfied. It is believed that the utilization of the multichannel strategy for ticketing is conducive to the sustainable development of public transportation and to passengers' travel behavior. As discussed by Birgelen et al. [1], channel performance satisfaction is directly associated with consumers' behavioral intentions. To provide appropriate and quality services, transportation organizations should understand the different factors affecting passengers' choice and preference in their utilization of distribution channels.

Since the multichannel strategy has become more widely adopted, channel performance has been paid greater 
attention by researchers [2]. In terms of critical factors affecting channel choice and preference, especially in retail shopping behavior, numerous studies on such issues have been conducted [1,3-6]. Regarding the transportation industry, there are many related researches on the application of a multichannel strategy for airlines [7-11], including research on the global distribution system (GDS) and the influence factors of ticketing channel choice, etc. Norazah and Norbayah [12] studied the intention of individuals to use a flight ticket booking app and found that the perceived usefulness represented the greatest influence on individuals with respect to their intention to engage with an app offered on a mobile device. Recent studies on a multichannel strategy employed by the railway industry have also increased. Some studies on railway passenger ticketing behavior, ticketing channel preference, and market segmentation have been conducted, as discussed in the research of Yung-Hsiang $[13,14]$ and Liu [15]. Though the multichannel strategy has already been commonly employed in the bus passenger transportation industry, relatively few research works are associated with this issue. In this paper, we attempted to gain a better understanding of the ticketing channel choice of bus transportation passengers through extending the work of previous researchers. The data were collected through both online and the paper-based questionnaire surveys, collected in Beijing in 2018. The questionnaire was designed with psychologists aiming to capture the fundamentals of ticketing behavior, including passengers' personal information, trip features, and their attitudes and perceptions towards various ticketing channels.

The rest of the paper is organized as follows. Section 2 provides a review of discrete choice models and presents the model formulation. Section 3 presents the data and sample characteristics. We present and discuss the estimation results of the models in Section 4. Section 5 summarizes and discusses the key findings of our research.

\section{Methodology}

2.1. Model on Choice Behavior. The previous research on channel choice has considered the consumer purchasing process as a sophisticated decision-making procedure. However, discrete choice analysis is supposed to be a proper approach for evaluating choice behavior and the decision process. Over the last few decades, numerous developments have been made within the field of discrete choice modeling in order to better unravel the underlying process leading up to observed choice outcomes. Behavior researchers have particularly attempted to improve models with the aim of enriching the collaboration of components of the decisionmaking process, such as attitudes, perception, incentives, etc. Reviewing the current literature indicates that decisionmakers' attitudes influence their parameter estimates [1620]. Schoenbachler and Gorden [3] illustrated that perceived risk, motivation to buy from a channel, product category, past direct marketing experience, and website design are important factors influencing consumers' channel choice. There are a variety of solutions that researchers have utilized to include attitudinal data. These methods are integrated in hybrid choice models (HCMs), which intend to fill the gap between discrete choice models and behavioral theories by illustrating explicitly unobserved elements of major cognitive processes [18, 21-23]. Among the numerous versions of HCMs is the explicit modeling of latent psychological factors such as attitudes and perceptions. The integrated choice and latent variable (ICLV) model inside the HCM conceptual framework permits the inclusion of attitudes, opinions, and perceptions by including latent attributes as descriptive variables within the utility function through structural equation modeling $[24,25]$. McFadden first proposed the ICLV model in 1986 [21], and many scholars, such as Ben-Akiva, Walker, Bhat, et al., developed these models [18, 26, 27]. In the last decade and a half, ICLV models have been increasingly applied in many fields to obtain a deeper understanding of the decision process of individuals [19, 25, 28-30]. Within the field of transportation, ICLV models have been deployed to investigate travel mode choice [31,32], route choice [33], shared-ride transportation service choice [34], flight choice [35], and so on. All the same, the reviewed literature shows that the ICLV model has not been applied to investigate the choice of transportation ticketing channels. Therefore, the aim of this study is to develop a ticketing channel choice ICLV model to analyze intercity bus passengers' ticketing channel preferences and choices.

2.2. Description of Ticketing Complexity. Ticket purchasing can be regarded as a kind of consumption behavior in the transportation industry, which is also a complex decisionmaking process. Apparently, there exists an objective complexity which can be evaluated as a role both of individual properties of the passenger such as gender, age, revenue, employment status, etc., and of the trip attributes, i.e., travel distance, departure time, etc. Apart from the objective factors listed above, choice behavior is affected by a number of not directly observable factors such as attitude, habit, perception, etc. It means that there is a perceived complexity which also influences passengers' behavioral responses and which is the subject of interest of our study.

We note that relevant research papers have adopted various kinds of channels, but most of them only focus on certain industries, especially within the retail industry [1]. Thus, we consider some major issues brought up by applying this model to the features of the bus passenger transportation industry, which thus guide the design of the present research. The first problem is the fact that users show strong concerns about privacy and security issues [36], as discussed by Gupta and Kim [37]. They report that perceived sacrifices prove to be a great barrier for consumers to employ certain distribution channels. The second issue is that the capability to process complex channel choice is apparently affected by sociodemographic factors such as gender, age, income, education level, etc., by mental ability and by familiarity with the choice channel as well as by emotional and mental state [38]. Furthermore, Gupta and Kim [37] illustrated that customers can decide upon different channels based on their evaluation of perceived value, which is customers' overall evaluation of the utility of perceived benefits and perceived 


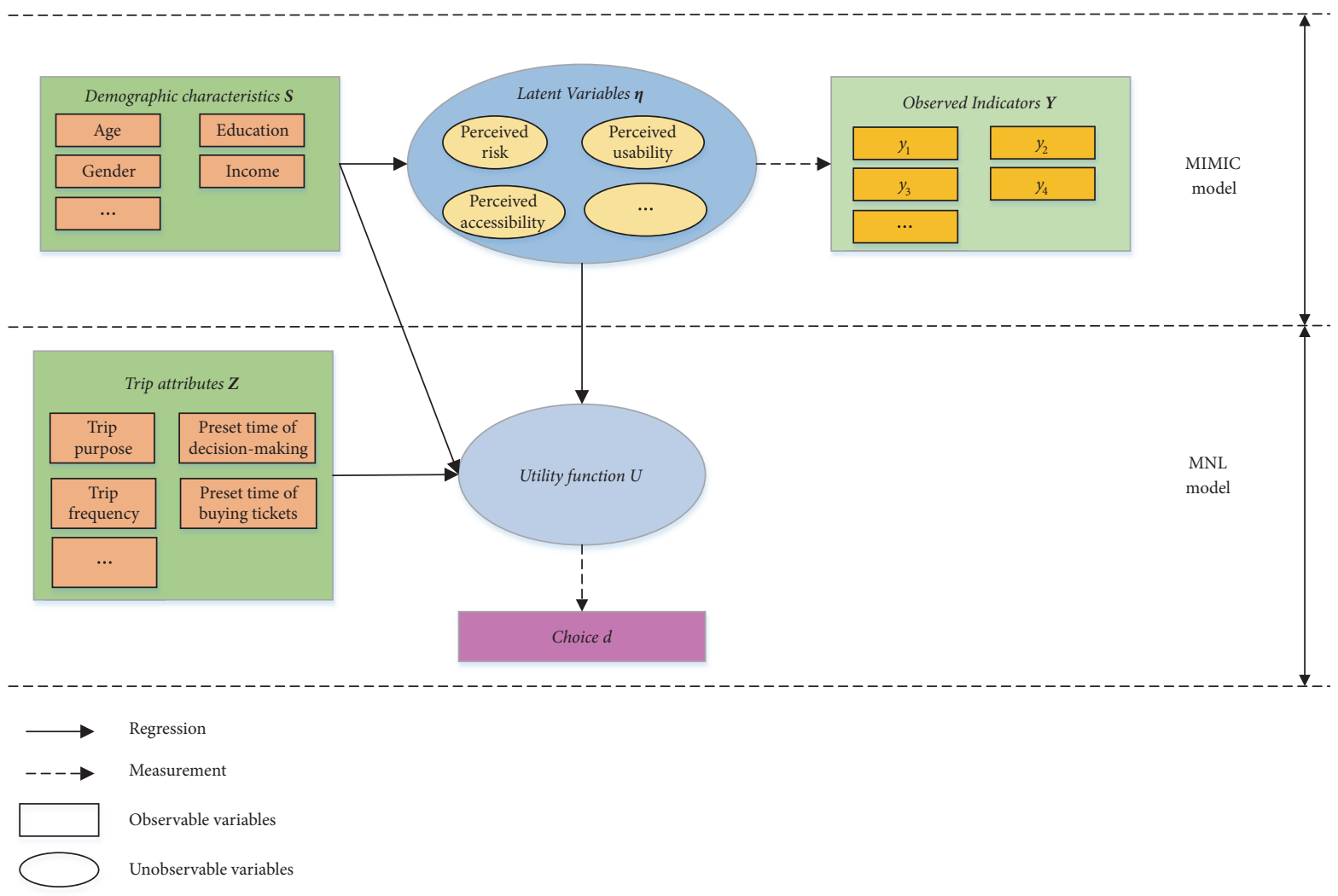

FigURE 1: Framework of the integrated choice and latent variable model.

sacrifices [39]. The perceived value of customer is defined as the net benefits (perceived benefits relative to perceived sacrifices) of an adoption. Basically, as discussed by Barberis and Huang [40], individuals exhibit loss aversion regarding purchasing decisions. Namely, consumers will not make a decision that involves a higher degree of perceived sacrifice than perceived benefits.

2.3. Modeling Approach. As discussed above, the consumers' internal process of preference formulation and the role of not directly observable factors such as attitudes, habits, etc. remain unexplained, forming the so-called black box in conventional discrete choice models. To address this challenge, this study provides a first attempt to employ an ICLV model which merges classic choice models with the structural equation model (SEM) for latent variables in order to deal with ticketing channel issues. The ICLV model consists of two main components: a choice model and a latent variable model, as shown in Figure 1. The latent variable model captures the idea that passengers' attitudes may affect their decision and can be measured by certain indicators. The choice model assumes that passengers' choices are based on the random utility maximization theory and that choices are influenced by two factors - the observed variables such as the sociodemographic characteristics of the decision-maker and attributes of the alternatives and the latent variables, which are captured by attitudinal indicators.
2.3.1. The Choice Model. The choice model is a multinomial logit (MNL) model that is utilized to analyze passengers' response to ticketing channel choice. The passenger $n(n=$ $1, \ldots, N)$ is faced with a set $C_{i}$ of alternatives $i(i=1, \ldots, M)$. Assuming a random utility maximization model, the passenger chooses the alternative which provides the maximum utility. The model relates the alternatives' utilities to observed and latent variables associated with the passengers and the alternatives.

$U_{i n}$ denotes the utility of alternative $i$ adopted by passenger $n . X_{\text {in }}$ describes the vector of the observed explanatory variables forming the systematic component $V$ of the utility $U_{i n} . L_{\text {in }}$ describes a vector of latent variables. $\varepsilon_{i n}$ represents the stochastic component of the utility $U_{i n}$. The utility $U_{\text {in }}$ is then expressed as follows:

$$
U_{i n}=V\left(X_{i n}, L_{i n} ; \theta, \beta\right)+\varepsilon_{i n}
$$

where $\theta$ and $\beta$ are the coefficient vectors that indicate the weight of the observed variables and the weight of the latent variables. Generally, the systematic component of the utility $U_{i n}$ is taken as a linear function:

$$
V_{i n}=\sum_{k} \theta_{i k} X_{i k n}+\sum_{l} \beta_{i l} L_{i l n} \quad k=1,2, \ldots, K
$$

where index $k$ refers to an observed variable and index $l$ refers to a latent variable. 
Assuming that $\varepsilon_{\text {in }}$ is an independently, identically distributed extreme value, the MNL choice model can be expressed as the following equation:

$$
P\left(y_{i n} \mid X_{i n}, L_{i n} ; \theta, \beta\right)=\frac{e^{V\left(X_{i n}, L_{i n}, \theta, \beta\right)}}{\sum_{j \in C_{M}} e^{V\left(X_{j n}, L_{j n}, \theta, \beta\right)}}
$$

where $y_{i n}$ is an indicator representing whether alternative $i$ is selected by individual $n$ or not, and (3) is obtained by

$$
y_{i n}= \begin{cases}1, & \text { if } U_{i n} \geq U_{j n} i \neq j \\ 0, & \text { otherwise. }\end{cases}
$$

2.3.2. The Latent Variable Model. The latent variable model is a MIMIC (Multiple Indicator Multiple Cause) model that consists of two submodels. The first is a structural model that represents the interrelationship between the latent variables and the observed explanatory variables. The formulation is expressed as follows:

$$
L_{i l n}=\sum_{r} \gamma_{i l r} X_{i r n}+\sum_{l} \beta_{i l n} L_{i l n}+\omega_{i l n}
$$

where index $r$ is an observed explanatory variable, while $\gamma$ and $\beta$ represent the parameters to be estimated. $\omega$ is error term with zero mean and standard deviation.

The second submodel is a measurement model which is a confirmatory factor analysis model linking the latent variables with their corresponding indicators. A linear factor model is specified to illustrate the mapping of the latent variables on the indicators and is expressed as follows:

$$
I_{i q n}=\sum_{l} \alpha_{i l q} L_{i l n}+\tau_{i q n}
$$

where index $q$ refers to an indicator. The parameter $\alpha$ shows which share of variance of the indicator $I$ is explained by the latent variable $L . \tau$ refers to the error term with zero mean and standard deviation.

The estimation of ICLV models is computationally complicated, and this complexity increases in proportion to the number of latent variables $[41,42]$. Sequential and simultaneous estimation methods are used to estimate the parameters involved in the ICLV modeling framework. The sequential method is a two-stage approach in which the structural equation model is estimated in a first step. In a second step, the resulting latent variables are entered in the choice models. Although this approach is straightforward and allowing the use of standard software for discrete choice and SEM [43], it is does not allow for latent variables impacting on each other. Therefore, the choice model and the latent variables model presented in this paper are estimated simultaneously. The model was estimated by using the SEM software package Mplus. For the joint estimation, the MLR estimator and for integration Monte Carlo simulation was used.

\section{Survey and Data}

3.1. Survey Design. The data used in this study originate from a survey that took place in Beijing, the capital of China, in March 2018. The questionnaire is designed with the aim of capturing passengers' ticketing channel choice behavior and the multidimensional nature of bus passenger transportation. There are four major sections in the questionnaire. The first section investigates ticketing channel choice through three questions. The second section contains 12 questions about attitude of passengers to the ticketing channel adopted. The third section includes six questions about trip characteristics of the respondents. The fourth section is composed of five questions focusing on the sociodemographic information of the passengers.

This study investigates demographic information, trip characteristics, and respondents' current ticketing channel choices. In terms of ticketing channel usage, we provided five distribution channels for respondents to choose from, including service counters at a station, ticketing agencies, tvms, websites, and apps. Passengers could mark their current choices across the ticket purchasing process, and this enabled us to understand passengers' current channel preference. We also investigated trip characteristics related to trip frequency, trip purpose, decision-making period prior to a given trip, and the timeframe prior to any given ticket purchase. We only required participants to report the current trip, including business trip or nonbusiness trip. The sociodemographic information collected in the last section of the questionnaire encompassed questions regarding gender, age, education background, occupation, monthly income, etc.

3.1.1. Measurement Items. In this study, we consider three latent constructs: perceived risk, perceived usability, and perceived accessibility. The first latent variable, perceived risk, shows an individual's concerns toward privacy and security issues. Miyazaki and Fernandez [36] emphasized that perceived risk is a great barrier when it comes to customers adopting certain distribution channels. Besides the risk of personal and trade information being released, this paper also considers financial risk, which is measured by the risk of billing errors during the ticketing process, as discussed by Mallat et al. [44]. The second latent variable, perceived usability, reflects the practical features of each ticketing channel. Previous research has underscored that several factors, such as efficiency, availability, time saving, and convenience, are important incentives for any purchase [45]. To fit the features of the bus passenger transportation, we consider information sought and advance ticketing in the questionnaire. The final latent variable, perceived accessibility, reflects whether the channel is easy to use or whether particular skills are required to use a certain channel. The items employed in this part are based on previous research $[45,46]$.

The indicators that are designed to measure the three attitudinal and perceptual latent variables are presented in Table 1. Each indicator is measured on a five-point Likert scale. The response scale ranges from 1 to 5 , with a response of 1 indicating that the participant completely disagreed with the statement and 5 indicating that they completely agreed. 
TABLE 1: Measurement items of latent variables.

\begin{tabular}{lcc}
\hline Latent Variable & Observed Indicator & Item Description \\
\hline$y_{1}$ & My personal information is protected in the process of purchasing a ticket \\
Perceived risk & $y_{2}$ & I am protected from fraud in the process of purchasing a ticket (e.g., fake ticket) \\
& $y_{4}$ & My ticketing habits and transaction records are not tracked \\
& $y_{5}$ & I can prevent a mistake from being made (e.g., billing error) \\
& $y_{6}$ & I receive clear, complete, and timely information about my trip \\
& $y_{7}$ & Using this channel, I can save time in the overall ticketing process \\
Perceived usability & $y_{8}$ & I can purchase my ticket efficiently \\
& $y_{9}$ & I can complete my transaction more conveniently \\
& $y_{10}$ & This channel is reliable and makes me feel reassured \\
Perceived accessibility & $y_{11}$ & It is easy access to this channel \\
$y_{12}$ & I can obtain clear operating instructions with this channel \\
\hline
\end{tabular}

3.2. Survey Administration. The survey was administered both on-field and online method. The paper-based questionnaire survey was conducted simultaneously at 7 stations for bus passenger transportation in Beijing. These 7 stations contain almost all the intercity bus passengers. The surveys were collected on March 6, 2018, and March 11, 2018. The surveyors team consisted of postgraduate and undergraduate university students. In order to avoid mistakes, the surveyors were sufficiently trained. The research team had a good cooperation with the intercity bus stations where the survey took place. There were 8 experienced surveyors at each station, who were deployed at the waiting hall during operating hours for data collection. Initially, respondents were approached and asked about their willingness to participate in the survey. After successful completion of the survey, respondents were rewarded with an umbrella to acknowledge their effort. However, respondents were free to agree on whether or not they wanted to participate in the survey. The mean completion time was 15.6 minutes of each survey. The number of surveys collected at each station are 79,70,65,89,101,58,72, respectively. From the 534 surveys, 491 were valid.

Comparison with traditional data-gathering methods, online methods present well due to inherent advantages of low cost, swiftness, and ease of storing data in databases. For the online survey, after the final web survey design was completed, the questionnaire was uploaded on survey website and ticketing app for 15 consecutive days. We recruited participants using different mechanisms. We contacted intercity bus operators and forums and asked them to forward to their members. Further, we disseminated survey information to social medias, such as Weibo and WeChat. For an extra incentive to participate, a draw of a present was organized for the respondents. It required 15 minutes to answer the online survey, while each survey took approximately 10-12 minutes. From the 1396 filled questionnaires, 1309 were acceptable.

\subsection{Data Analysis}

3.3.1. Descriptive Statistics Analysis. The sample used for the modeling process consists of 1800 participants, of which 491 are on-field surveys and 1309 are online surveys. Majority of people who take intercity bus are floating population rather than resident population in Beijing. For this reason, we set out to obtain a sample that provided good coverage and enough sample of various income, age, and gender rather than strictly being population-proportional. Moreover, in this study, only intercity bus passengers were surveyed and asked about their ticketing channel choice behavior. The sample in this case has got certain advantages. Firstly, a relatively larger sample could be obtained due to higher response rates among users who have used an intercity bus for their trip. Secondly, this dataset could contain more expert opinions than is generally obtained from a larger sample.

Table 2 presents the demographic information, trip characteristics, and the usage of each channel of the respondents. It shows that more than half $(54.8 \%)$ of the respondents are between 26 and 55 years old. $44.7 \%$ of the respondents are male. $37.5 \%$ of the respondents are migrant workers. Most of the respondents have a monthly income between $3000 \mathrm{CNY}$ and $9000 \mathrm{CNY}$. Approximately 60\% of the respondents have lower education than a college level. $45 \%$ of the respondents' trip purpose are business. In terms of the usage of different ticket channels, $34.8 \%$ of respondents used counter at the station to purchase tickets. Although intercity bus operators have endeavored to develop the mobile ticketing, the usage rate of Apps (21.9\%) is relatively lower than counter.

Table 3 presents the scores of the measurement items for perceptions. It shows that $\mathrm{y}_{2}$ has the highest scores, indicating that respondents are concerned about financial and personal information issues. On the other hand, $\mathrm{y}_{6}$ and $\mathrm{y}_{10}$ have the lowest scores, but with the largest standard deviations, indicating that respondents hold different attitudes toward easy use of the ticket channel.

In Tables 2 and 3, the difference between the online and on-field survey has been compared by $p$ value. We find that there is no significant difference between the respondents of both samples. With respect to the two samples surveyed in two days of the on-field survey, there are no significant differences in sociodemographic characteristics between the respondents of both samples. In terms of the trip purpose, the percentage of business trip on weekday is higher than that on weekend, with $49.7 \%$ on weekday versus $22.22 \%$ on weekend. 


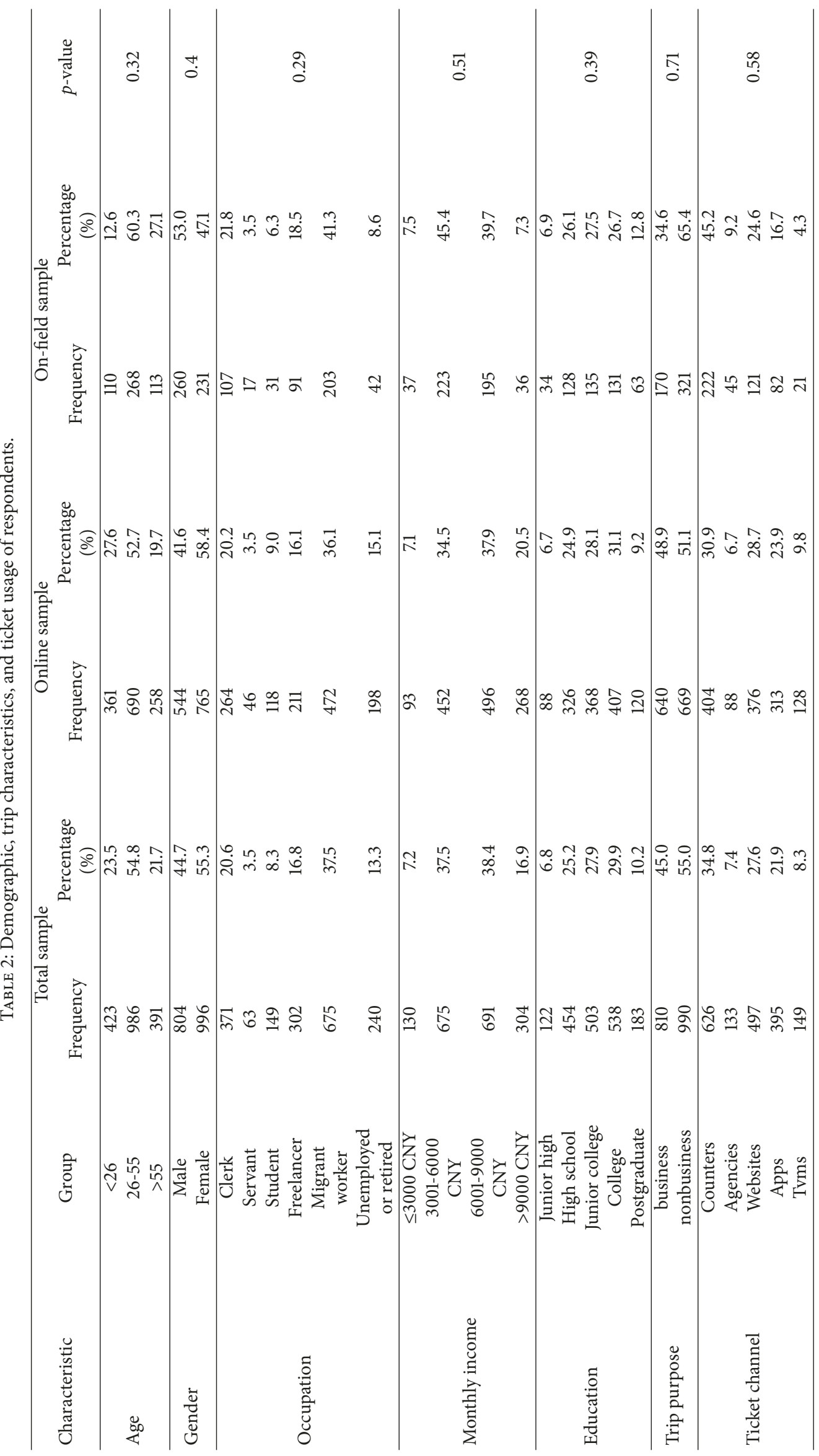


TABLE 3: Scores of the measurement items for perceptions.

\begin{tabular}{|c|c|c|c|c|c|c|c|}
\hline \multirow{2}{*}{ Observed Indicator } & \multicolumn{2}{|c|}{ Total sample } & \multicolumn{2}{|c|}{ Online sample } & \multicolumn{2}{|c|}{ On-field sample } & \multirow{2}{*}{$\begin{array}{c}p \text {-value } \\
\text { (online vs. on-field) }\end{array}$} \\
\hline & Mean & S.D. & Mean & S.D. & Mean & S.D. & \\
\hline $\mathrm{y}_{1}$ & 3.95 & 0.78 & 4.29 & 0.65 & 3.61 & 0.81 & 0.43 \\
\hline $\mathrm{y}_{2}$ & 4.32 & 0.80 & 4.38 & 0.92 & 4.26 & 0.76 & 0.19 \\
\hline $\mathrm{y}_{3}$ & 3.59 & 1.16 & 2.98 & 1.08 & 4.20 & 1.21 & 0.81 \\
\hline $\mathrm{y}_{4}$ & 4.05 & 0.79 & 4.09 & 0.67 & 4.01 & 0.82 & 0.72 \\
\hline $\mathrm{y}_{5}$ & 4.24 & 0.88 & 4.71 & 0.93 & 3.77 & 0.81 & 0.38 \\
\hline $\mathrm{y}_{6}$ & 2.55 & 1.36 & 3.12 & 1.56 & 1.98 & 1.21 & 0.16 \\
\hline $\mathrm{y}_{7}$ & 3.74 & 1.07 & 3.91 & 1.02 & 3.57 & 1.18 & 0.90 \\
\hline $\mathrm{y}_{8}$ & 3.99 & 1.02 & 4.01 & 0.87 & 3.97 & 1.23 & 0.53 \\
\hline $\mathrm{y}_{9}$ & 4.20 & 0.67 & 3.01 & 0.89 & 5.39 & 0.61 & 0.34 \\
\hline $\mathrm{y}_{10}$ & 2.43 & 1.19 & 2.59 & 1.28 & 2.27 & 0.97 & 0.39 \\
\hline $\mathrm{y}_{11}$ & 4.03 & 0.80 & 4.01 & 0.95 & 4.05 & 0.76 & 0.26 \\
\hline $\mathrm{y}_{12}$ & 4.31 & 0.75 & 3.98 & 0.61 & 4.64 & 0.92 & 0.87 \\
\hline
\end{tabular}

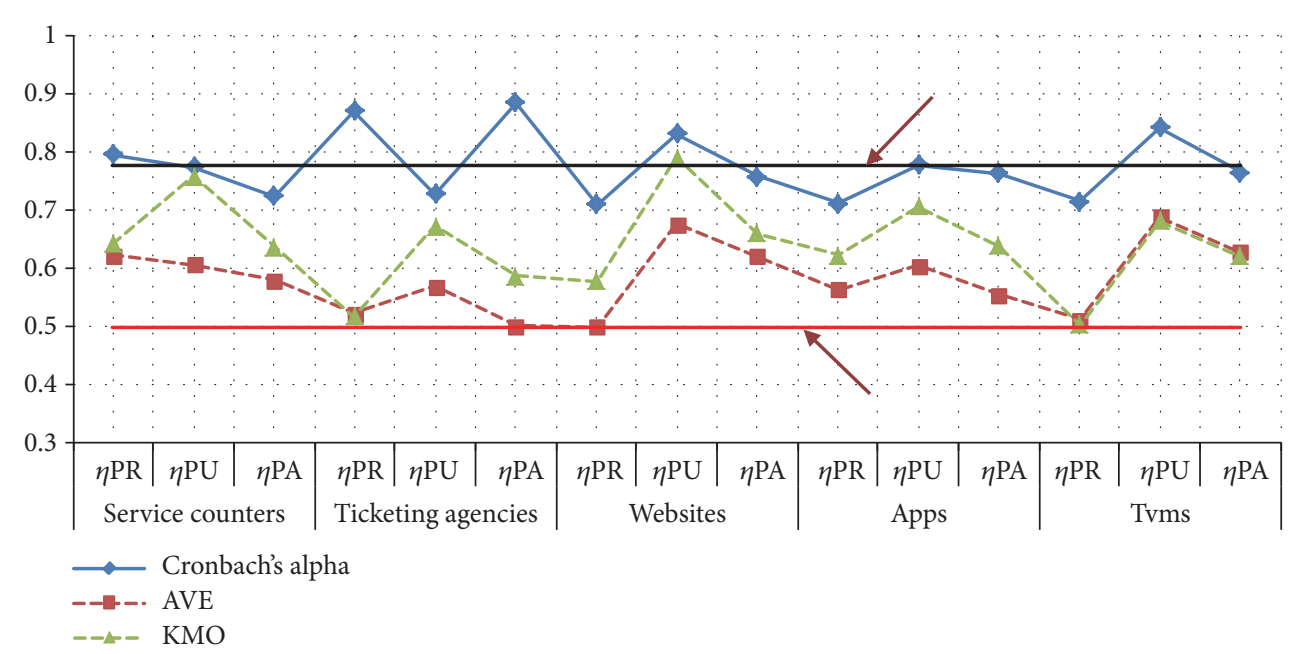

FIGURE 2: Reliability and validity tests of the sample.

Respondents surveyed on weekday are found to more likely use the website and Apps channel. The percentage of online channel usage was $54.62 \%$ on weekday versus $28.85 \%$ on weekend.

3.3.2. Latent Constructs. In order to ensure that all the samples are consistent and stable, we used Cronbach's alpha to test the reliability of the latent variables. At the same time, we adopted Average Variance Extracted (AVE) and Kaiser-Meyer-Olkin (KMO) tests to guarantee a qualified validity. Reliability and validity tests of the sample are shown in Figure 2.

Figure 2 shows Cronbach's alpha of each latent variable to be greater than 0.7 , which indicates that the observed items of each latent variable are consistent. Moreover, Figure 2 also shows that the results of the AVE and KMO tests are greater than 0.5 , which means the observed items we constructed reflect the latent conception well.

The indicators scores of the three latent variables are presented in Figure 3. In terms of perceived risk, offline channels (counters, ticketing agencies) score higher than online

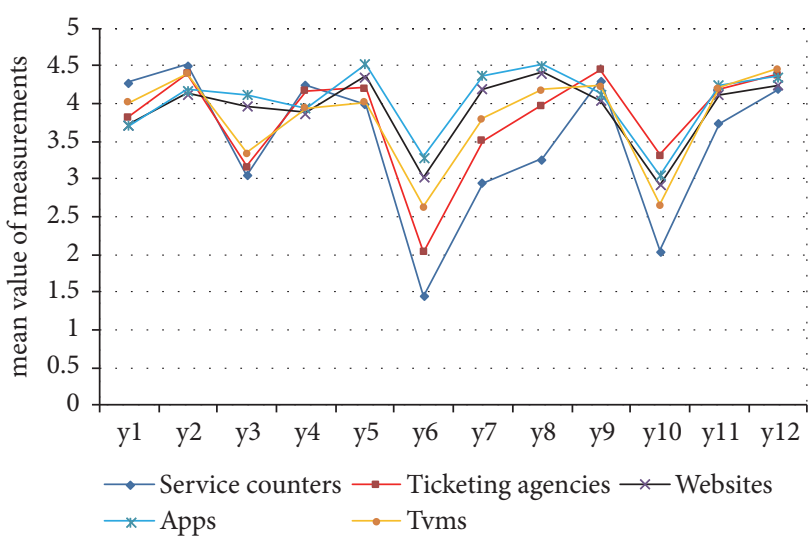

FIgURE 3: Indicators scores of the three latent variables.

ones (websites, apps) as a whole. A possible explanation is that Internet fraud has become serious in recent years. Thus, particularly when phone numbers and identification numbers are required, passengers may hesitate between 
TABLE 4: Annotations of the observed variables.

\begin{tabular}{|c|c|c|}
\hline Variables & Annotation & Formulation \\
\hline Age & $S_{\text {age }}$ & $=1 \mid$ age $<26 ;=2 \mid 26 \leq$ age $\leq 55 ;=3 \mid$ age $>55$ \\
\hline Gender & $S_{\text {gen }}$ & $=1 \mid$ male $;=0 \mid$ female \\
\hline Occupation & $S_{\text {occ }}$ & $\begin{array}{l}=1 \mid \text { clerk } ;=2 \mid \text { servant } ;=3 \mid \text { student }=4 \mid \text { freelancer; } \\
=5 \mid \text { migrant worker }=6 \mid \text { unemployed or retired }\end{array}$ \\
\hline Income & $S_{\text {inc }}$ & $\begin{array}{l}=1 \mid \text { income } \leq 3000 \mathrm{CNY} ;=2 \mid 3000 \mathrm{CNY}<\text { income } \leq 6000 \mathrm{CNY} \\
=3 \mid 6000 \mathrm{CNY}<\text { income } \leq 9000 \mathrm{CNY} ;=4 \mid \text { income }>9000 \mathrm{CNY} \\
=1 \mid \mathrm{edu}=\text { junior high }=2 \mid \mathrm{edu}=\text { high school }\end{array}$ \\
\hline Education (edu) & $S_{\text {edu }}$ & $\begin{array}{l}=3 \mid \text { edu }=\text { junior college } ;=4 \mid \text { edu }=\text { college } \\
=5 \mid \text { edu }=\text { postgraduate }\end{array}$ \\
\hline Trip purpose & $Z_{\mathrm{tp}}$ & $=1 \mid$ business $;=2 \mid$ nonbusiness \\
\hline Preset time of decision-making $(\mathrm{dm})$ & $Z_{\mathrm{dm}}$ & $=1|d m=1 ;=2| 1<\mathrm{dm} \leq 3 ;=3|4<\mathrm{dm} \leq 7 ; 4| \mathrm{dm}>7$ \\
\hline Preset time of buying tickets (bt) & $Z_{\mathrm{bt}}$ & $=1|\mathrm{bt}=1 ;=2| 1<\mathrm{bt} \leq 3 ;=3|4<\mathrm{bt} \leq 7 ; 4| \mathrm{bt}>7$ \\
\hline Frequency of the coach (fr) & $Z_{\text {fr }}$ & $=1|\mathrm{fr} \leq 2 ;=2| 3 \leq \mathrm{fr} \leq 5 ;=3|6 \leq \mathrm{fr} \leq 10 ;=4| \mathrm{fr}>10$ \\
\hline
\end{tabular}

TABLE 5: Goodness of fit indices of Multiple Indicator Multiple Cause (MIMIC) submodels.

\begin{tabular}{|c|c|c|c|c|c|}
\hline Fitness Index & Counters & Ticketing Agencies & Websites & Apps & Tvms \\
\hline$\chi^{2} / d f$ & 2.596 & 2.763 & 2.875 & 3.529 & 2.578 \\
\hline CFI (Comparative Fit Index) & 0.906 & 0.981 & 0.929 & 0.932 & 0.891 \\
\hline TLI (Tucker-Lewis Index) & 0.949 & 0.905 & 0.951 & 0.916 & 0.915 \\
\hline SRMR (Standardized Root Mean Squared Residual) & 0.040 & 0.039 & 0.048 & 0.049 & 0.039 \\
\hline RMSEA (Root Mean Squared Error of Approximation) & 0.076 & 0.040 & 0.068 & 0.762 & 0.790 \\
\hline
\end{tabular}

choosing online over offline channels. In terms of perceived usability, time saving and efficiency show significant discrepancies between channels and are commonly considered important drivers that affect channel preference. Compared with counters, apps and websites greatly satisfy the desire for efficiency of passengers, as indicated by the higher score of online channels. This is consistent with previous studies [47]. In terms of perceived accessibility, the mean score of ticketing agencies is higher than the scores of other channels. Compared to service counters at a station, ticketing agencies greatly fulfill passengers' requirements for the fast and easy receipt of tickets as soon as they complete payment. Generally speaking, ticketing agencies are widely spread over the city, meaning that they provide better accessibility compared to service counters or tvms that are located at peripheral locations with no direct rapid transit connection, as discussed by Cheng [48]. In addition, tvms perform well over other channels in $y_{12}$; this result implies that passengers want to obtain full assistance from the station clerk when they encounter difficulties in operating the ticketing system or may not be familiar with the ticketing apps or websites.

\section{Results and Discussion}

This section presents and discusses the estimation results of the model. In the MIMIC model that relates the latent variables to observed explanatory variables, we considered age, gender, occupation, income, and education levels as potential explanatory variables. In the ticketing channel choice model, we considered additional trip-specific variables (such as purpose, frequency, etc.), as well as the latent variables themselves. Annotations and discretization results of the observed variables are represented in Table 4. Preset time of decision-making $(\mathrm{dm})$ means that what time in advance the passengers decide this travel. Preset time of buying tickets (bt) means that what time in advance the passengers decide to purchase their ticket. Frequency of the coach (fr) means the number of the departure buses per day.

4.1. Latent Variables-Structural and Measurement Models. Taking into account the discrepancy of the effect and choice mechanism between channels, we develop counters, ticketing agencies, websites, apps, and tvms MIMIC submodels, respectively, in this section. Several goodness of fit indices of the models are presented in Table 5.

To achieve good model fit, it is recommended that CFI and TLI should be greater than 0.9 [49]. In addition to that, an acceptable value of RMSEA should be lower than the cutoff value of 0.08 [50], and it is considered a good fit if the value of SRMR is lower than 0.05 [51]. Table 5 indicates that $\chi^{2} / d f$ of each channel is smaller than 3 , except that of apps, which is still within an acceptable threshold. In terms of the goodness of fit index, the CFI and TLI are greater than 0.9. In addition, the SRMR is smaller than 0.05 and the RMSEA is smaller than 0.08. From the indices listed in Table 5, there is confidence that all the five MIMIC models are fit for further analysis.

(1) Effects on Latent Variables Dependent upon Demographic Characteristics. The effects of demographic characteristics on 


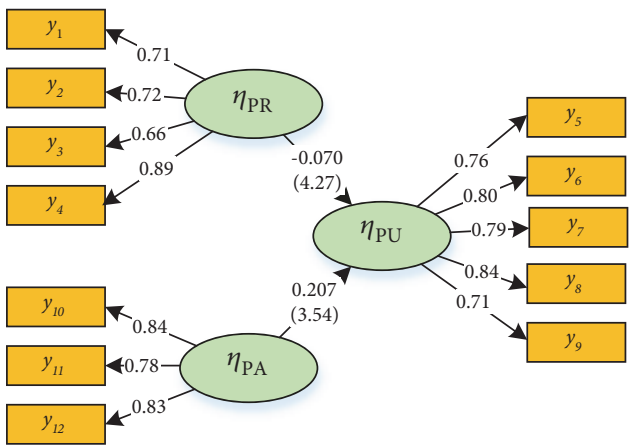

FIGURE 4: MIMIC submodel for service counters.

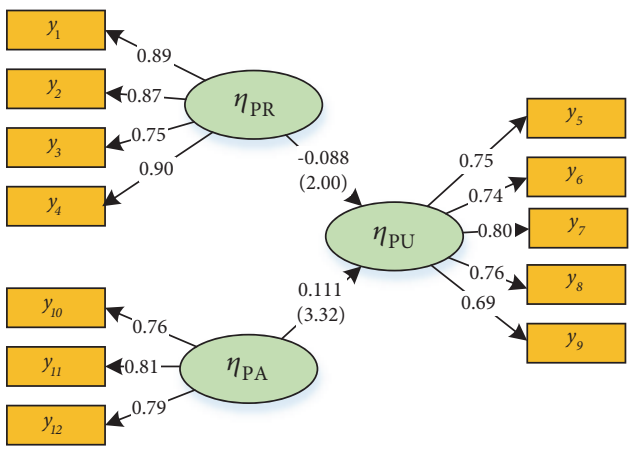

FIgURE 5: MIMIC submodel for ticketing agencies.

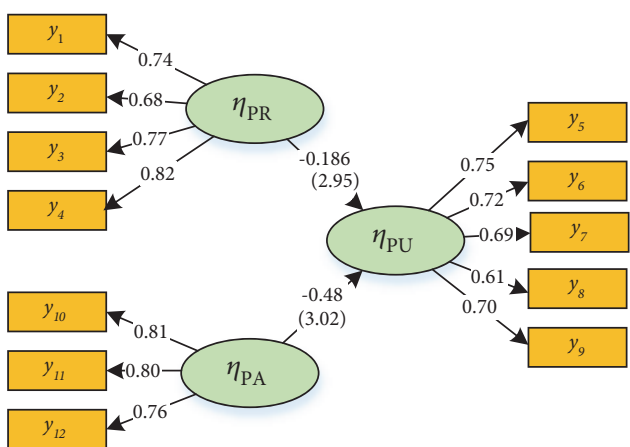

Figure 6: MIMIC submodel for websites.

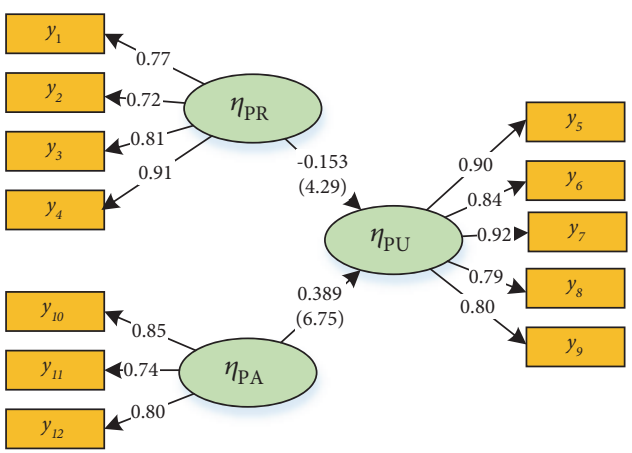

FIgURE 7: MIMIC submodel for apps. latent variables are analyzed. There are five independent variables under consideration: age, gender, occupation, income, and education. Both the standardized weight coefficient and $t$-value were calculated and listed in Table 6; the $t$-value is shown in the parentheses.

Table 6 shows that the structural model of online channels outperforms over the model of offline channels. With regard to websites, apps, and tvms, the latent variables that we proposed are more likely to be affected by demographic characteristics. However, the effects on each latent variable vary a lot among different channels, and not every demographic characteristic has a significant impact, e.g., age.

Though widely investigated in the field of retail consumption, the influence of perceived risk on ticketing choice has not been studied thoroughly before. This paper indicates that the perceived risk seems not to be affected by demographic characteristics, except the age. In the choice of websites, elder passengers have a high perceived risk than the younger, while it is quite the contrary in tvms.

With regard to the effects on the perceived usability, the age is insignificant. Specifically, young passengers who have a higher income tend to feel pleased with the functions provided by apps and tvms. In contrast, elder passengers feel a higher perceived usability of the website channel. Besides, education was also shown to have a significant positive effect on this latent variable in the channel choice of apps. It is implied that operators should improve the design quality of apps for passengers with a lower education background, which make up the majority of intercity bus passengers in
Beijing according to our investigation. It should be noted that the occupation does have influence on the latent variable, but the perceived usability of the websites and the ticketing agencies only.

Perceived accessibility is significantly affected by the education towards the choice of online channels. The positive coefficient indicates that better educated passengers will have a higher value of the perceived accessibility. What is more, age still plays an important role of the perceived accessibility in the choice of apps, partly because of the lower popularity of the smart phone among the old people.

(2) Analysis of the Relationship between Latent Variables. The results of the measurement model for different channels are presented in Figures $4-8$. The numbers on the arrows display the estimated values of the standardized coefficient, while the $t$-values are listed in parentheses only if the given value is significant at a confidence of $95 \%$.

It can be seen from Figures $4-8$ that exogenous variables like $\eta_{\mathrm{PR}}$ and $\eta_{\mathrm{PA}}$ have a significant effect on the endogenous variable $\eta_{\mathrm{PU}}$ under the level of $p=0.001$, with a contribution of the total variance up to $60 \sim 85 \%$. This reveals that risk and accessibility are the fundamental factors that play important roles in ticketing channel choice through the intervening variable, i.e., usability, which is the straightforward consideration.

Taking service counters as an example, this has long been the predominant channel for passengers because counters are free of complicated operations, as embodied in the positive 


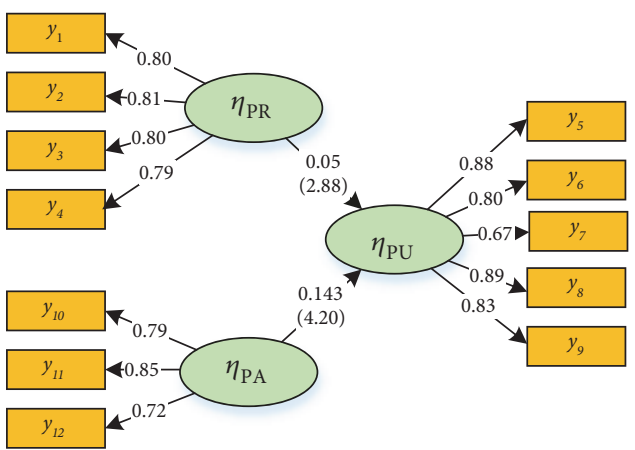

FIgURE 8: MIMIC submodel for tvms.

high weight of $\eta_{\mathrm{PA}}$ on $\eta_{\mathrm{PU}}$ in the MIMIC model. Similarly, in the model for apps, there is an even higher effect on perceived usability. This means that preferences have not changed since online channels have become available, and accessibility still remains an important and primary need. Nevertheless, perceived risk weakens the usability drawn from the negative coefficient, which is smaller for counters, reflecting the pessimistic views toward the current situation of Internet fraud, etc. On the contrary, tvms combine the advantages of online and offline channels together, and tickets are immediately printed out as the bill paid. It can be seen from Figure 8 that the coefficient between $\eta_{\mathrm{PR}}$ and $\eta_{\mathrm{PU}}$ approaches zero and the coefficient between $\eta_{\mathrm{PA}}$ and $\eta_{\mathrm{PU}}$ is significantly positive. This shows that tvms provide a good experience for passengers and remarkably alleviate the pressure on counters as well.

4.2. Channel Choice Model. In the following, both results from a conventional choice model and from an integrated choice and latent variable model are presented, in order to gain insight into the process of passengers' decision-making and to assess to what extent the inclusion of the latent variable model provides additional explanatory power compared with a classic choice model, as discussed by Heike [52].

The estimation results of the ICVL model and MNL model without latent variables are presented in Table 7 . The MNL model is only used as a base model for testing the stability of estimated parameters in the ICLV model. The most important asset of the estimated ICLV model is its capability to gain insights into the effect of key factors on the choice to different ticketing channels.

Overall, the estimated values of the parameters are in agreement with prior expectations. From the perspective of constant terms, websites seem more attractive than counters and ticketing agencies, but less so compared to apps. Interestingly, in this case, the constants do seem to reflect the preference of bus passengers in Beijing. Indeed, more and more people are using smartphones and the Internet in China.

Not surprisingly, the explanatory variables have a significant impact on ticketing channel choice. Compared with the websites channel, passengers with a low level of education are more likely to choose offline channels, which offer them a more accessible way to obtain necessary assistance. Meanwhile, passengers with a higher income demonstrate a tendency to choose websites or apps; it is also discussed by Cheng [53]. In addition, passengers whose travel decisions are made that day have a higher probability of choosing counters or tvms, following traditional habits all the time. Moreover, offline channels were found to be less popular among students. On the contrary, online channels provide specific and accessible information about schedules, seats, and so on, which is convenient for those who feel unsettled.

Table 7 also shows that the latent variables significantly affect channel choice. The influence of the three latent variables differs in the ICLV model. For example, perceived usability has a negative impact on the choice of ticketing agencies. Likewise, the sensitivity of the factors varies a lot. Taking the websites channel as an example, the probability of this choice is reduced by $21 \%$ when the score of perceived risk is raised by one point.

The results also show that the $\mathrm{R}^{2}$ improves from 0.379 for MNL to 0.435 for the ICLV model. The differences might be due to the absence of latent variables in the MNL model that led to the underestimation of the significance of most of the sociodemographic and trip-specific variables in explaining the preference heterogeneity. Therefore, it can be said that the perception has a significant effect on the ticketing channels choice.

\section{Conclusions}

In the last decade, discrete choice models have evolved to include an explicit recognition of psychological factors, enabling us to gain a deeper understanding of the decision processes of individuals. One such model formulation is the ICLV model, which is increasingly being considered in many fields. The aim of this study is to develop a ticketing channel choice ICLV model to analyze intercity bus passengers' ticketing channel preferences and choices. To the authors' knowledge, this paper presents the first ICLV model in field of ticketing channel choice behavior for bus passenger transportation.

5.1. Findings. The data used for the model estimation originate from a survey that took place in Beijing in March 2018, which was administered through both online and paperbased questionnaires. In our research, we include three latent psychological factors to explain ticketing channel choice: perceived risk, perceived usability, and perceived accessibility. The indicators for these constructs are collected in the survey on a five-point Likert ordinal scale. Our study shows that the three latent variables play significant roles in ticketing channel choice. In terms of perceived risk, passengers are more concerned about privacy and anti-fraud, especially for online channels. In terms of perceived usability, time saving and efficiency are primary incentives, while convenience also should be taken into consideration.

The ICVL and MNL model, as a base model, are estimated in this study. The result shows that the $R^{2}$ improved from 0.379 for MNL to 0.435 for the ICLV model. It can be 


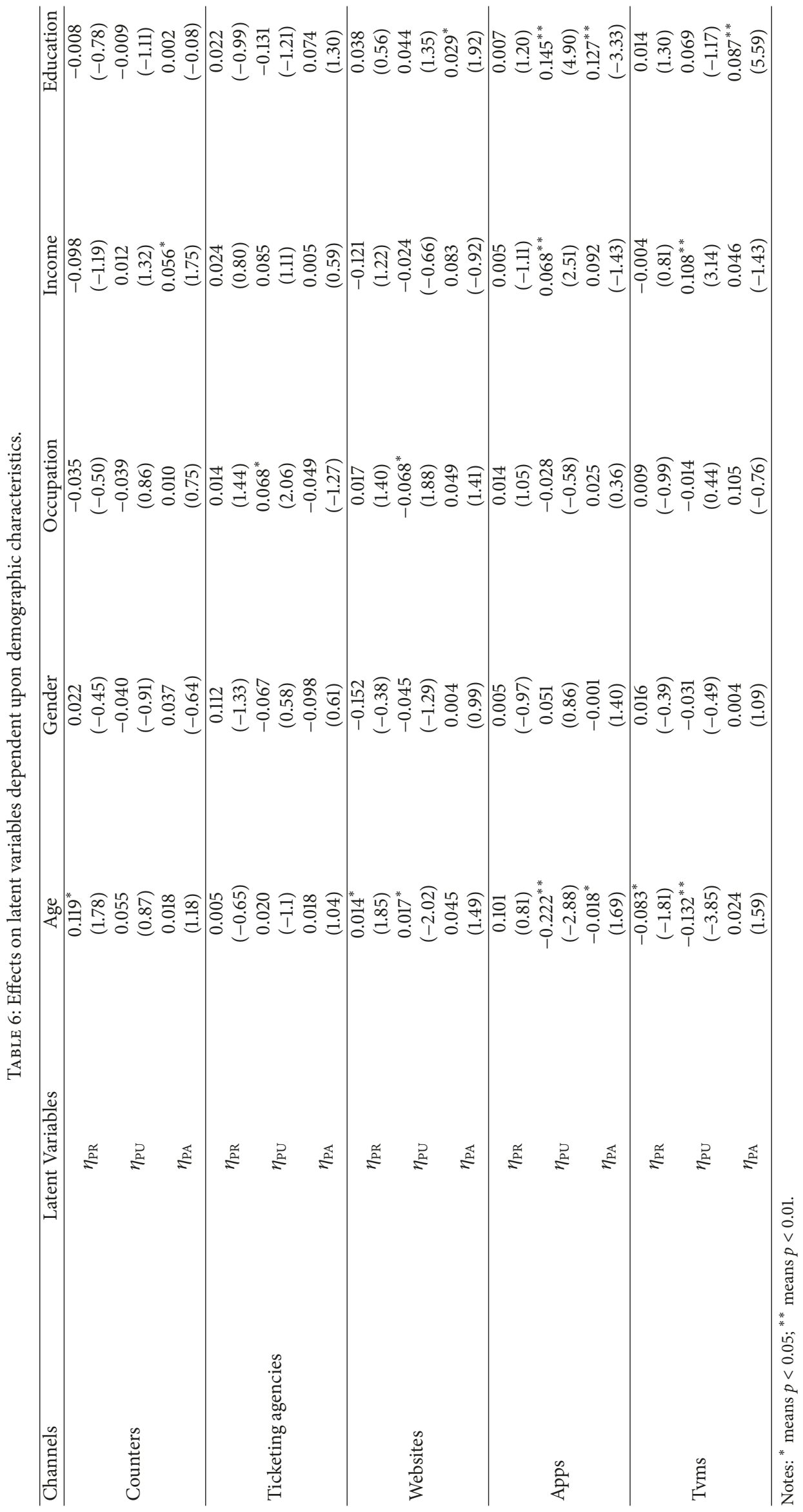


TABLE 7: Comparison of the estimation results.

\begin{tabular}{|c|c|c|c|c|c|c|c|c|}
\hline \multirow{2}{*}{ Variables } & \multicolumn{4}{|c|}{ Integrated choice and latent variable model } & \multicolumn{4}{|c|}{ Multinomial logit (MNL) model } \\
\hline & Counters & Ticketing Agencies & Apps & Tvms & Counters & Ticketing Agencies & Apps & Tvms \\
\hline Constant & $-1.076^{*}$ & -0.132 & $1.531^{* *}$ & -0.105 & -1.002 & -0.15 & 1.011 & 0.183 \\
\hline$S_{\text {age }}$ & 0.819 & $11.55^{*}$ & -0.586 & $0.128^{*}$ & 1.392 & $15.79^{*}$ & $-0.839^{*}$ & $0.212^{* *}$ \\
\hline$S_{\text {gen }}$ & $1.855^{* *}$ & -0.219 & $-1.206^{* *}$ & 0.532 & $0.557^{* *}$ & -0.598 & 0.851 & 0.022 \\
\hline$S_{\text {occ }}$ & $1.329^{*}$ & $2.257^{*}$ & -0.281 & $-12.769^{*}$ & 1.032 & $0.409^{* *}$ & $-0.667^{*}$ & $-0.175^{*}$ \\
\hline$S_{\text {inc }}$ & 0.972 & 0.311 & $1.056^{*}$ & 0.657 & $0.751^{*}$ & $0.219^{*}$ & 0.971 & 0.356 \\
\hline$S_{\text {edu }}$ & 3.197 & 2.988 & 1.336 & 0.715 & 2.187 & 3.15 & 1.159 & 1.76 \\
\hline$Z_{\mathrm{tp}}$ & $-0.196^{*}$ & $-0.803^{* *}$ & 0.033 & $-0.901^{* *}$ & -0.083 & -3.5 & $1.902^{*}$ & $0.026^{*}$ \\
\hline$Z_{\mathrm{dm}}$ & -0.597 & -0.169 & 0.891 & $-0.359^{*}$ & $-0.081^{*}$ & $-0.453^{*}$ & $0.661^{* *}$ & 0.229 \\
\hline$Z_{\mathrm{bt}}$ & $1.794^{* *}$ & $1.208^{*}$ & $-0.926^{*}$ & 3.971 & 1.097 & 1.946 & 0.061 & $2.667^{* *}$ \\
\hline$Z_{\mathrm{fr}}$ & -0.898 & $-10.238^{*}$ & $0.121^{* *}$ & -0.303 & -1.186 & 9.927 & $0.198^{*}$ & -0.664 \\
\hline$\eta_{\mathrm{PR}}$ & $0.279^{*}$ & 0.13 & 1.07 & 0.398 & - & - & - & - \\
\hline$\eta_{\mathrm{PU}}$ & -0.39 & $-0.35^{*}$ & $1.362^{*}$ & $0.18^{*}$ & - & - & - & - \\
\hline$\eta_{\mathrm{PA}}$ & 0.17 & 0.271 & 0.117 & 0.138 & - & - & - & - \\
\hline Samples & \multicolumn{4}{|c|}{1800} & \multicolumn{4}{|c|}{1800} \\
\hline likelihood & \multicolumn{4}{|c|}{2981.77} & \multicolumn{4}{|c|}{1761.29} \\
\hline log-likelihood & \multicolumn{4}{|c|}{-100.87} & \multicolumn{4}{|c|}{-589.26} \\
\hline $\mathrm{R}^{2}$ & \multicolumn{4}{|c|}{0.435} & \multicolumn{4}{|c|}{0.379} \\
\hline
\end{tabular}

Notes: ${ }^{*}$ means $p<0.05 ;{ }^{* *}$ means $p<0.01$.

said that the latent variables are found to be significantly affecting the ticketing channel choice behavior. Therefore, it is also indicated that not only observed sociodemographic and trip characteristics, but also psychological characteristics are important issues impacting the process of ticketing decisionmaking.

Furthermore, the results indicate that passengers with different sociodemographic and trip characteristics have differing preferences regarding ticketing channels. Generally speaking, young or highly paid people tend to buy tickets through online channels such as apps or websites, while old or poorly educated people tend to choose counters or ticketing agencies.

5.2. Policy and Managerial Implications. The findings are very useful for researchers and authorities dealing with bus passenger transportation issues. In particular, a bus passenger transportation operation agency may better understand the real needs of passengers and reallocate relevant resources to the appropriate channels. Although the mobile channel is developing rapidly, the use of offline channels remains the favorite among passengers in this study. The intercity bus operators should offer incentives for passengers to use online channel. At the same time, they must demonstrate protective mechanisms for privacy and financial information to eliminate passengers' concerns.

Passengers with various sociodemographics have different needs for ticketing channel preference. This implies a need to adopt different marketing strategies so as to precisely and effectively influence ticketing choice behavior. For the younger and female passengers who prefer to purchase ticket online, operators can optimize the function of the ticketing website and provide precision and timely travel information.
The elderly passengers and the passengers with low income are more likely to purchase tickets at the service counter and the ticketing agent. Operators should improve the quality and service level of ticket sale to better meet the needs of such passenger groups.

5.3. Limitations and Future Research. Although this study provides an appropriate modeling approach for dealing with ticketing channel choice behavior, several research directions remain to be explored in future studies. The empirical case was conducted in Beijing, and this research did not emphasize the potential perception differences caused by the various nature of the transportation industry. Future studies are suggested to collect passengers' related information based on the research area. Moreover, the data used in this study were collected by a questionnaire survey. Some of the variables, such as cost of the fare, knowledge of the system, and current payment options, have not been included in the model. It is recommended that passive data collection technology be used to enhance the model, such as databases collected by ticketing software.

\section{Data Availability}

The data used to support this study incorporate personal information of participants. Considering the protection of personal information, the data are partly available from the corresponding author upon request.

\section{Conflicts of Interest}

The authors declare no conflicts of interest. 


\section{Acknowledgments}

The authors appreciate the support from the Beijing Transportation Information Center and the Beijing Liuliqiao road passenger station in research data collection. This research was supported by the National Natural Science Foundation of China (No. 71390332).

\section{References}

[1] M. van Birgelen, A. de Jong, and K. de Ruyter, "Multi-channel service retailing: The effects of channel performance satisfaction on behavioral intentions," Journal of Retailing, vol. 82, no. 4, pp. 367-377, 2006.

[2] N. A. Agatz, M. Fleischmann, and J. A. van Nunen, "Efulfillment and multi-channel distribution - A review," European Journal of Operational Research, vol. 187, no. 2, pp. 339-356, 2008.

[3] D. D. Schoenbachler and G. L. Gordon, "Multi-channel shopping: understanding what drives channel choice," Journal of Consumer Marketing, vol. 19, no. 1, pp. 42-53, 2002.

[4] S. Farag, T. Schwanen, M. Dijst, and J. Faber, "Shopping online and/or in-store? A structural equation model of the relationships between e-shopping and in-store shopping," Transportation Research Part A: Policy and Practice, vol. 41, no. 2, pp. 125141, 2007.

[5] A. Alptekinoğlu and C. S. Tang, "A model for analyzing multichannel distribution systems," European Journal of Operational Research, vol. 163, no. 3, pp. 802-824, 2005.

[6] K. Wang, Y. Zhao, Y. Cheng, and T.-M. Choi, "Cooperation or competition? Channel choice for a remanufacturing fashion supply chain with government subsidy," Sustainability, vol. 6, no. 10, pp. 7292-7310, 2014.

[7] E. Bigné, B. Hernández, C. Ruiz, and L. Andreu, "How motivation, opportunity and ability can drive online airline ticket purchases," Journal of Air Transport Management, vol. 16, no. 6, pp. 346-349, 2010.

[8] F. Alamdari and K. Mason, "The future of airline distribution," Journal of Air Transport Management, vol. 12, no. 3, pp. 122-134, 2006.

[9] C. Delcea, L. Cotfas, and R. Paun, "Agent-Based Evaluation of the Airplane Boarding Strategies' Efficiency and Sustainability," Sustainability, vol. 10, no. 6, p. 1879, 2018.

[10] L. A. Garrow, S. Hotle, and S. Mumbower, "Assessment of product debundling trends in the US airline industry: Customer service and public policy implications," Transportation Research Part A: Policy and Practice, vol. 46, no. 2, pp. 255-268, 2012.

[11] J. I. Castillo-Manzano and L. López-Valpuesta, "The decline of the traditional travel agent model," Transportation Research Part E: Logistics and Transportation Review, vol. 46, no. 5, pp. 639649, 2010.

[12] N. Mohd Suki and N. Mohd Suki, "Flight ticket booking app on mobile devices: Examining the determinants of individual intention to use," Journal of Air Transport Management, vol. 62, pp. 146-154, 2017.

[13] Y. Cheng, "Evaluating web site service quality in public transport: evidence from taiwan high speed rail," Transportation Research Part C: Emerging Technologies, vol. 19, no. 6, pp. 957974, 2011.

[14] Y. Cheng and T. Huang, "High speed rail passengers' mobile ticketing adoption," Transportation Research Part C: Emerging Technologies, vol. 30, pp. 143-160, 2013.
[15] F.-X. Liu, Q.-Y. Peng, H.-B. Liang, Z.-J. Fu, and B. Zhang, "Highspeed railway passenger ticketing behavior characteristics based on PCA and clustering," Journal of Transportation Systems Engineering and Information Technology, vol. 17, pp. 126-132, 2017.

[16] C. R. Bhat, "Endogenous segmentation mode choice model with an application to intercity travel," Transportation Science, vol. 31, no. 1, pp. 34-48, 1997.

[17] S. Choo and P. L. Mokhtarian, "What type of vehicle do people drive? The role of attitude and lifestyle in influencing vehicle type choice," Transportation Research Part A: Policy and Practice, vol. 38, no. 3, pp. 201-222, 2004.

[18] M. Ben-Akiva, D. Mcfadden, K. Train et al., "Hybrid choice models: progress and challenges," Marketing Letters, vol. 13, no. 3, pp. 163-175, 2002.

[19] J. Walker and M. Ben-Akiva, "Generalized random utility model," Mathematical Social Sciences, vol. 43, no. 3, pp. 303-343, 2002.

[20] M. Kamargianni and A. Polydoropoulou, "Hybrid choice model to investigate effects of teenagers' attitudes toward walking and cycling on mode choice behaviour," Transportation Research Record, no. 2382, pp. 151-161, 2013.

[21] D. McFadden, "The choice theory approach to market research," Marketing Science, vol. 5, no. 4, pp. 275-297, 1986.

[22] D. Mcfadden, M. Ben-Akiva, and T. Morikawa, "Discrete choice models incorporating revealed preferences and psychometric data," Advances in Econometrics, vol. 16, no. 1, pp. 29-55, 2002.

[23] M. V. Johansson, T. Heldt, and P. Johansson, "The effects of attitudes and personality traits on mode choice," Transportation Research Part A: Policy and Practice, vol. 40, no. 6, pp. 507-525, 2006.

[24] E. Figueroa-García, J. García-Machado, and D. PérezBustamante Yábar, "Modeling the social factors that determine sustainable consumption behavior in the community of madrid," Sustainability, vol. 10, no. 8, article 2811, 2018.

[25] A. Vij and J. L. Walker, "How, when and why integrated choice and latent variable models are latently useful," Transportation Research Part B: Methodological, vol. 90, pp. 192-217, 2016.

[26] J. L. Walker and J. Li, "Latent lifestyle preferences and household location decisions," Journal of Geographical Systems, vol. 9, no. 1, pp. 77-101, 2007.

[27] C. R. Bhat and S. K. Dubey, "A new estimation approach to integrate latent psychological constructs in choice modeling," Transportation Research Part B: Methodological, vol. 67, pp. 6885, 2014.

[28] D. Temme, M. Paulssen, and T. Dannewald, "Incorporating latent variables into discrete choice models - a simultaneous estimation approach using SEM software," Business Research, vol. 1, no. 2, pp. 220-237, 2008.

[29] R. A. Daziano and D. Bolduc, "Incorporating pro-environmental preferences towards green automobile technologies through a Bayesian hybrid choice model," Transportmetrica A: Transport Science, vol. 9, no. 1, pp. 74-106, 2013.

[30] T. Rossetti, C. A. Guevara, P. Galilea, and R. Hurtubia, "Modeling safety as a perceptual latent variable to assess cycling infrastructure," Transportation Research Part A: Policy and Practice, vol. 111, pp. 252-265, 2018.

[31] M. Kamargianni, S. Dubey, A. Polydoropoulou, and C. Bhat, "Investigating the subjective and objective factors influencing teenagers' school travel mode choice - an integrated choice and latent variable model," Transportation Research Part A: Policy and Practice, vol. 78, pp. 473-488, 2015. 
[32] M. L. Outwater, S. Castleberry, Y. Shiftan, M. Ben-Akiva, Y. Shuang Zhou, and A. Kuppam, "Attitudinal market segmentation approach to mode choice and ridership forecasting: structural equation modeling," Transportation Research Record, vol. 1854, no. 1, pp. 32-42, 2003.

[33] C. R. Bhat, S. K. Dubey, and K. Nagel, "Introducing nonnormality of latent psychological constructs in choice modeling with an application to bicyclist route choice," Transportation Research Part B: Methodological, vol. 78, pp. 341-363, 2015.

[34] Z. Al-Ayyash, M. Abou-Zeid, and I. Kaysi, "Modeling the demand for a shared-ride taxi service: An application to an organization-based context," Transport Policy, vol. 48, pp. 169182, 2016.

[35] A. Fleischer, A. Tchetchik, and T. Toledo, "The impact of fear of flying on travelers' flight choice," Journal of Travel Research, vol. 51, no. 5, pp. 653-663, 2011.

[36] A. D. Miyazaki and A. Fernandez, "Consumer perceptions of privacy and security risks for online shopping," Journal of Consumer Affairs, vol. 35, no. 1, pp. 27-44, 2001.

[37] S. Gupta and H. Kim, "Value-driven Internet shopping: The mental accounting theory perspective," Psychology \& Marketing, vol. 27, no. 1, pp. 13-35, 2010.

[38] J. Altmann, B. Rupp, and P. Varaiya, "Effects of pricing on Internet user behaviour," Netnomics, vol. 3, no. 1, pp. 67-84, 2001.

[39] V. A. Zeithaml, "Consumer perceptions of price, quality, and value: a means-end model and synthesis of evidence," Journal of Marketing, vol. 52, no. 3, pp. 2-22, 1988.

[40] N. Barberis and M. Huang, "Mental accounting, loss aversion, and individual stock returns," The Journal of Finance, vol. 56, no. 4, pp. 1247-1292, 2001.

[41] F. J. Bahamonde-Birke and J. d. Ortúzar, "On the variability of hybrid discrete choice models," Transportmetrica A: Transport Science, vol. 10, no. 1, pp. 74-88, 2012.

[42] M. F. Yáñez, S. Raveau, and J. D. D. Ortúzar, "Inclusion of latent variables in mixed logit models: modelling and forecasting," Transportation Research Part A: Policy and Practice, vol. 44, no. 9, pp. 744-753, 2010.

[43] S. Raveau, R. Álvarez-Daziano, M. F. Yáñez, D. Bolduc, and J. De Dios Ortúzar, "Sequential and simultaneous estimation of hybrid discrete choice models," Transportation Research Record, vol. 2156, pp. 131-139, 2010.

[44] N. Mallat, M. Rossi, V. K. Tuunainen, and A. Öörni, "An empirical investigation of mobile ticketing service adoption in public transportation," Personal and Ubiquitous Computing, vol. 12, no. 1, pp. 57-65, 2008.

[45] J. M. Cheng, G. Sheen, and G. Lou, "Consumer acceptance of the internet as a channel of distribution in Taiwan - a channel function perspective," Technovation, vol. 26, no. 7, pp. 856-864, 2006.

[46] T. Ahn, S. Ryu, and I. Han, "The impact of the online and offline features on the user acceptance of Internet shopping malls," Electronic Commerce Research and Applications, vol. 3, no. 4, pp. 405-420, 2004.

[47] R. T. Frambach, H. C. Roest, and T. V. Krishnan, “The impact of consumer Internet experience on channel preference and usage intentions across the different stages of the buying process," Journal of Interactive Marketing, vol. 21, no. 2, pp. 26-41, 2007.

[48] Y. Cheng, "High-speed rail in Taiwan: New experience and issues for future development," Transport Policy, vol. 17, no. 2, pp. 51-63, 2010.
[49] B. Byrne, Structural Equation Modeling with AMOS: Basic Concepts, Applications, and Programming, Routledge Academic, Ontario, Canada, 2nd edition, 2010.

[50] L. Hu and P. M. Bentler, "Cutoff criteria for fit indexes in covariance structure analysis: conventional criteria versus new alternatives," Structural Equation Modeling, vol. 6, no. 1, pp. 155, 1999.

[51] T. F. Golob, "Structural equation modeling for travel behaviour research," Transportation Research Part B: Methodological, vol. 37, no. 1, pp. 1-25, 2003.

[52] H. Link, "Is car drivers' response to congestion charging schemes based on the correct perception of price signals?" Transportation Research Part A: Policy and Practice, vol. 71, pp. 96-109, 2015.

[53] Y.-H. Cheng and T.-Y. Huang, "High speed rail passenger segmentation and ticketing channel preference," Transportation Research Part A: Policy and Practice, vol. 66, no. 1, pp. 127-143, 2014. 


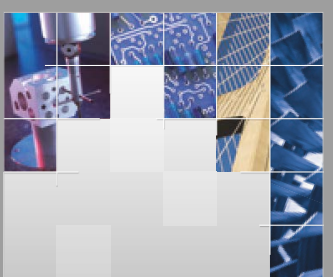

\section{Enfincering}
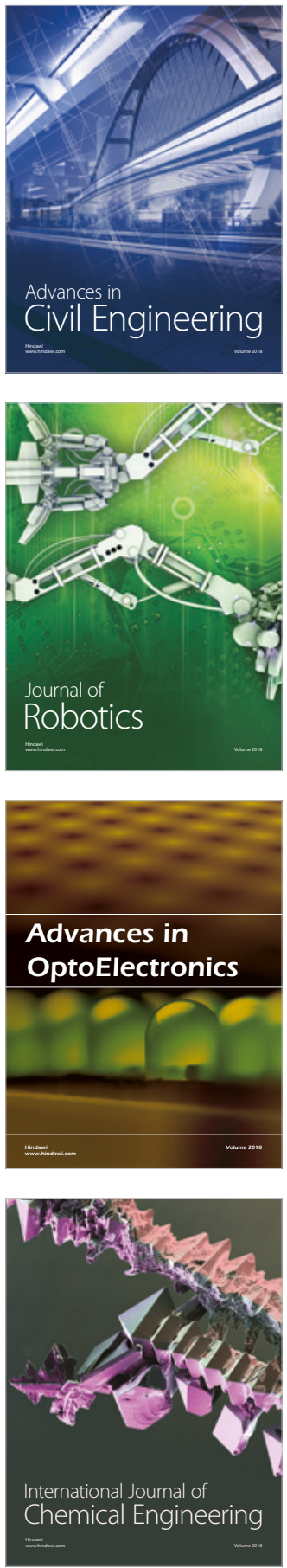

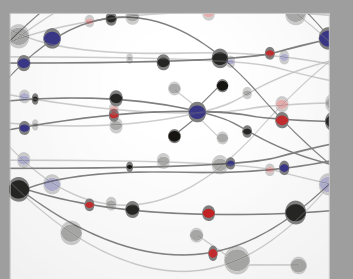

\section{Rotating \\ Machinery}

The Scientific World Journal

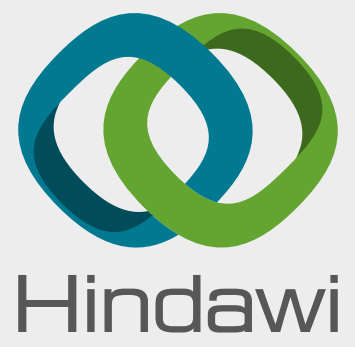

Submit your manuscripts at

www.hindawi.com
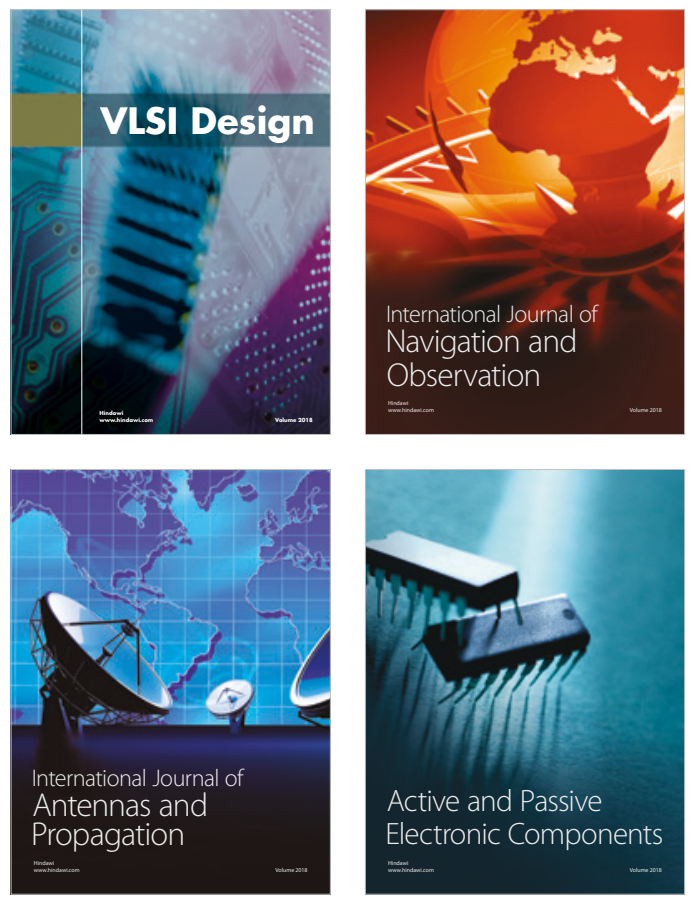
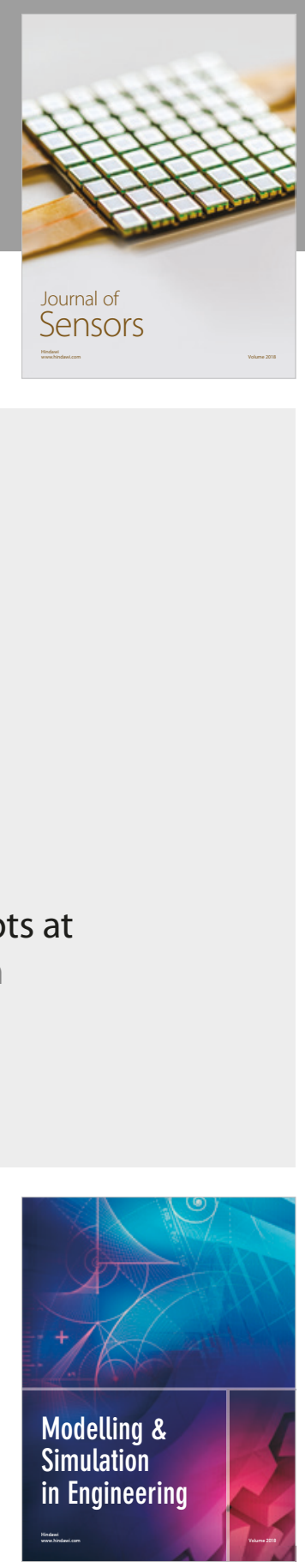

\section{Advances \\ Multimedia}
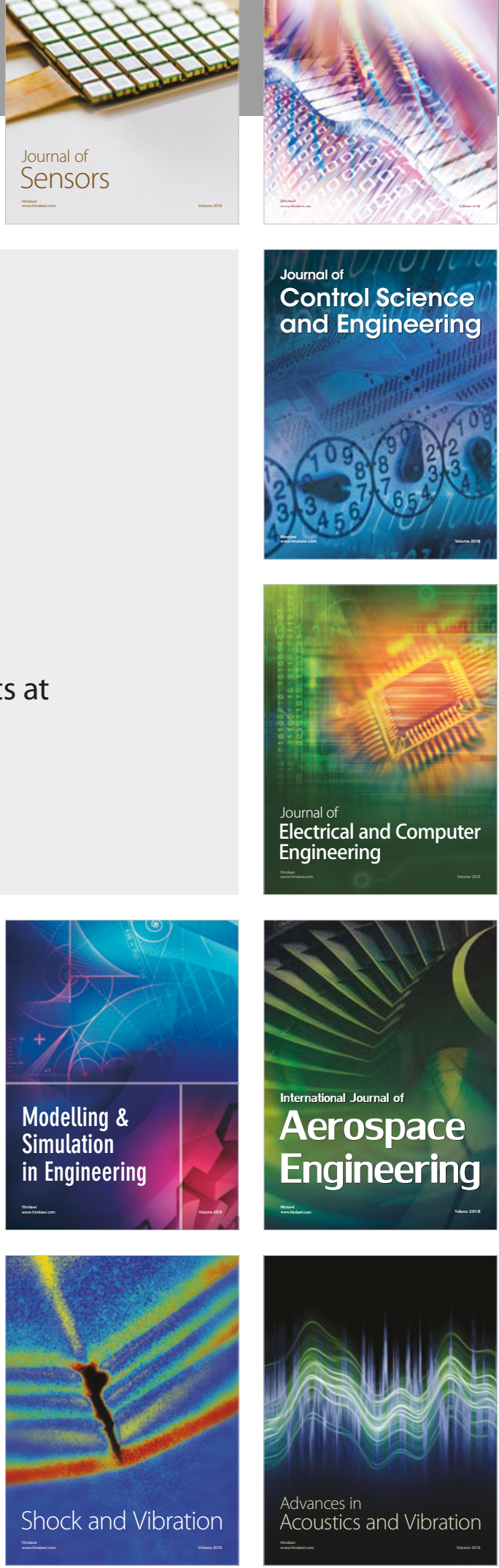